\title{
Cidadania, racismo e mídia: a identidade do negro ${ }^{1}$
}

\section{Citizenship, racism and the media: the identity of the black}

\author{
Kalyne Menezes ${ }^{1}$ \\ (mskalyne@gmail.com) \\ Simone Antoniaci Tuzzo ${ }^{2}$ \\ (simonetuzzo@hotmail.com)
}

\begin{abstract}
Resumo
Este trabalho sobre mídia e cidadania, aborda questões ligadas ao racismo tomando como referência as obras de Muniz Sodré que tratam do racismo e da estética grotesca do negro na televisão. Outros autores também apoiam a discussão em cidadania, contribuindo com temas como identidade, comunidade, grupos e cidadania. Para a discussão, também se fez necessário um breve contexto histórico sobre o negro na sociedade brasileira, principalmente após a abolição da escravatura. $\mathrm{O}$ texto também discorre sobre os conceitos de cidadania, que interferem diretamente na concepção do sujeito como "cidadão" e as ideias de comunidade, estética de padrões, valores e representação dos afrodescendentes pela mídia, além de discriminação e formas de exclusão e o significado da palavra negrotesco explicado com muita propriedade por Muniz Sodré.
\end{abstract}

Palavras-chave: Mídia. Cidadania. Racismo. Grotesco.

\begin{abstract}
This paper discusses media and citizenship, addressing issues related to racism taking as reference Muniz Sodré's works about racism and grothesque aesthetics and black television. Other authors also support the discussion in citizenship, contributing to subjects like identity, community, groups and citizenship. In this discussion, is also necessary to make a brief historic context about black people in brazilian society, mainly after the slavery abolishment. This text is also about the concepts of citizenship which is intrinsically related to the conception of the subject as a "citizen" and the ideas of community, aesthetics standards, the values and the media's representation of the afrodescendant people, besides discriminations and different ways of excluding, and the meaning of the word negrotesco well explained by Muniz Sodré.
\end{abstract}

Keywords: Media. Citizenship. Racism. Grotesque.

\footnotetext{
${ }^{1}$ Kalyne Menezes é jornalista pela Universidade Federal de Goiás, UFG, e mestranda em Comunicação pela mesma instituição, área de pesquisa em mídia e cidadania.

${ }^{2}$ Simone Antoniaci Tuzzo é Doutora em Comunicação pela UFRJ, Mestre e Graduada em Comunicação pela UMESP, Coordenadora do Projeto de Pesquisa Rupturas Metodológicas para uma leitura crítica da Mídia entre os Programas de Pós-Graduação da UFG e UFRJ, que integra a ação transversal no 06/2011 - Casadinho/Procad. Professora e Orientadora do Trabalho desenvolvido na Disciplina Seminários Temáticos de Mídia e Cidadania - PPGCOM - UFG.
} 


\section{Introdução}

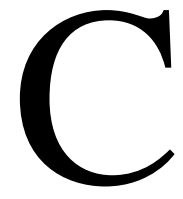

idadania é um termo cunhado desde a Grécia Antiga que, de lá para cá, sofreu diversas mudanças no próprio conceito, influenciadas pelas sociedades e suas demandas. Para além de ser compreendida como um direito, a cidadania está intrinsecamente ligada à uma qualidade de vida, a um status, a um ser cidadão. Tornar-se cidadão é ocupar o lugar de sujeito, participante e ativo, na sociedade em que se vive. Partindo da polis como lugar ontológico do homem, Muniz Sodré destaca a cidadania ligada ao conceito de política e de democracia desde a Grécia até os dias atuais. É cidadão aquele que participa do fato de governar e ser governado.

A democracia, por sua vez, representa o poder das tribos e, na modernidade, pode ser entendida como um mecanismo de governo e também como uma construção simbólica posta a serviço da soberania popular. Em Sodré, conceito de cidadania é o que melhor expressa a democracia. Cidadania é constituída de direitos plenos (direitos políticos e sociais). Sodré destaca o espaço público como o espaço mediador da cidadania em seus termos clássicos, realizando a mediação dos interesses particulares da sociedade civil. Assim, é cidadão - e exerce a cidadania quem está visível na cena pública. Na Grécia antiga, tornar-se visível no espaço comum estava na base da atividade política.

Sodré enfatiza que a democracia é uma construção simbólica posta a serviço da soberania popular e, compartilhando o pensamento com Coutinho, salienta que o conceito de cidadania é o que melhor expressa a democracia. Para Coutinho (2000, apud SODRÉ 2006, p. 129), "Cidadania é a capacidade conquistada por alguns indivíduos, ou [...] por todos os indivíduos, de se apropriarem dos bens socialmente criados, de atualizarem todas as potencialidades de realização humana abertas pela vida social em cada contexto historicamente determinados”. Entretanto, não há nada de natural na política, nem na democracia nem na cidadania. Todas implicam relações de poder.

No Brasil, tomando como eixo central a questão do negro, a noção de cidadania começou a aparecer oriunda dos movimentos e ideias liberais europeus. Após a abolição da escravatura, as elites brasileiras estavam num processo de construção da nação, pelo viés do embranquecimento e valores europeus, e "respeitavam" as culturas negras, pois não era de bom tom ignorá-las. Por outro lado, o negro, que já sofria uma marginalização por ter carregado o peso da escravidão, agora lutava por um espaço na sociedade brasileira e afirmações de identidade, enfrentando o racismo e a exclusão social. Reflexo dessa longa história do Brasil, a mídia reproduziu os valores vigentes na 
sociedade e, apesar das conquistas dos movimentos sociais e do reconhecimento das identidades, culturas e comunidades afro-brasileiras, a mídia ainda corrobora com o racismo, mesmo que indiretamente. É o negro como grotesco, o "negrotesco” de Muniz Sodré.

\title{
1 Identidade, cidadania e racismo
}

A identidade liga o sujeito a um quadro de referência e promove uma intersecção entre história individual e do grupo com o qual convive, o que leva a um reconhecimento social de si mesmo no outro. A partir da identidade individual, também se cria uma identidade nacional, carregada de símbolos. A ideia de grupo impõe-se como a de um outro 'lugar", onde o indivíduo sente pluralmente e, por essa identificação, é espaço de luta por causas similares, engajamento e exercício da cidadania. Empenho do cidadão na experiência política, com vistas à plena realização da humanidade do sujeito. A comunidade, por sua vez, pode ser entendida como um horizonte simbólico de relações definidas por vínculos afetivos profundos, que implicam um compromisso ético com um projeto existencial a político.

Discorrendo sobre Habermas, Sodré (1999) argumenta que o autor situa o problema da cidadania no âmbito de uma oposição entre universalismo e particularismo, fazendo distinção entre uma cultura política (baseada no universalismo das instituições liberais, assegurando democracia e direitos humanos) e cultura etnográfica ou subcultura, sustentada pelo particularismo dos usos e costumes locais ou regionais.

\begin{abstract}
Num contexto multiculturalista, isto é, de aproximação de subculturas dentro de um Estado-nação, registram-se normalmente conflitos entre a cultura hegemônica e os grupos particularistas. Habermas admite a possibilidade de convivência do universalismo político com as particularidades culturais, ou seja, que não haja direitos coletivos para os particularismos. (SODRÉ, 1999, p. 20-21)
\end{abstract}

Sodré afirma que identidade designa um "completo relacional que liga o sujeito a um quadro contínuo de referências, constituído pela intersecção de sua história individual com a do grupo onde vive”. A identidade de alguém só é possível em função de um outro, ou seja, só se reconhece a um "si mesmo" reconhecendo um "outro", com suas ideologias, crenças, valores, padrões cognitivos.

Toda cultura afirma-se como "unidade de identificações" (SODRÉ 1999), buscando solucionar a diversidade das partes. A identidade obtida através da cultura, afirma Sodré, permite 
idealizar as relações sociais que instituem a cidadania, já que estão diretamente ligadas às ideologias formadoras dos indivíduos e dos grupos aos quais pertencem.

A ideia de grupo impõe-se como a de um outro "lugar", onde o indivíduo sente pluralmente. No grupo ou em sua cultura, pode ter-se a percepção de estruturas globais, experimentar sensações na totalidade, pois, sendo ele a forma que dá substrato à tensão luz/trevas, é uma fonte permanente de excitações. Polimorfa, a organização grupal contem os mais diversos modos de funcionamento psíquico e o horizonte das modulações existenciais dos indivíduos. Por isso, pode alguém dizer, como Jacques Lacan, que é o "coletivo" (leia-se também os grupos) é o "sujeito individual." (SODRÉ, 1999, p. 141)

Nos grupos estão indivíduos ligados por laços de sangue, etnia, território, religião ou até mesmo a um projeto consensual. É um agrupamento humano, uma comunidade. O conceito de comunidade, explica Sodré, não implica mais o cidadão, sujeito isolado. Mas "o homem como um todo, o ser holístico apoiado na tradição e no espírito" (Sodré, 2002, p. 177). A ideia de comunidade aproxima-se mais do conceito de pertencimento a um mesmo grupo humano.

Na comunidade está implicada a ideia de uma continuidade, derivada não dos atributos de uma entidade ou da propriedade de uma substancia comum (seja sangue, território, um laço cultural, etc), e sim da partilha de um múnus, que é a luta comum pelo valor, isto é, pelo que obriga cada individuo a obrigar-se com o outro. Tal é a dívida simbólica, transmitida de uma geração para outra por indivíduos imbuídos da consciência de uma obrigação, tanto para os ancestrais...quanto para com os filhos... (SODRÉ, 2002, p. 178)

O conceito de cidadania surgiu antes dos renascentistas designando um conjunto de indivíduos, grupo, como entidade representativa de relações de poder entre o todo e a parte, homogêneo e heterogêneo. O grupo, enfatiza Sodré, implica uma redefinição da ideia de comunidade. Na Modernidade, passou-se a conhecer os padrões de vida e as formações comunitárias (corporações, associações, aldeias) e as doutrinas racionalistas e liberais "fizeram a história suspeitar da ideia de comunidade, erigindo como valor supremo da consciência" (SODRÉ, 1992).

Pereira (1999) coloca que os direitos individuais e coletivos do homem começaram a ganhar destaque na Europa ocidental a partir do século XVII, tendo como um dos pontos de partida o liberalismo, cuja igualdade entre os homens é algo comum às diferentes concepções. Seriam os homens portadores de direitos naturais e não concedidos pela sociedade. "Essencial frisar que toda 
essa discussão se dava num mundo branco. O que não era branco, era outro mundo”. (PEREIRA, 1999).

Somente a partir dos programas de bem-estar social implantados na Europa a partir do pós Segunda Guerra Mundial, é que se configura plenamente o conceito liberal de cidadania, definido pela visão clássica de T. H. Marshall. Essa cidadania seria uma consagração legal e formal dos direitos sociais, somados aos já conquistados direitos civis e diretos políticos.

No Brasil, as limitações do conceito de cidadania refletem em grande parte as disputas internas de poder das classes dominantes, mas também as dificuldades de posicionamento e de mobilização dos movimentos sociais (PEREIRA, 1999). Com a derrota do liberalismo ético na Europa e com o abolicionismo no Brasil, o negro foi liberto pela Lei Áurea, mas tinha apenas uma garantia legal e formal. A marginalização dos afro-brasileiros se acentuava a partir desse momento e ficou mais evidente com a chegada do capitalismo e os mecanismos de transição econômica. O viés do racismo atravessa todas as relações políticas, econômicas e ideológicas no Brasil.

As oligarquias rurais brasileiras lançaram mão do escravo em detrimento da mão de obra imigrante, "com a concepção arianista (que se tornou política de Estado), e que preconizava a substituição do povo como condição para se constituir uma nação de verdade. Os grandes fazendeiros lançaram mão da imigração para a agricultura e outros setores profissionais urbanos" (PEREIRA, 1999). A solução imigracionista era não somente uma resposta ao problema da escassez de mão de obra, mas também parte de um projeto de modernização do país, cujo branqueamento era um ponto desejado.

Pereira explica isso a partir de Muniz Sodré (1999), que utiliza o conceito de "lógica patrimonial", em oposição ao simples interesse econômico. Não era apenas um fator econômico em jogo, mas uma supremacia econômica e institucional que perpetuava uma série de valores que as classes dominantes colocavam suas perspectivas na construção da nação, do sistema de poder.

...o escravo era (gerava) valor; com a nova legislação, ou se tornava cidadão, ou... Ter-se-ia que dar um jeito. Foi, então, "transformado" em negro (estigma recheado de negatividade, capaz de minar a assunção plena da sua cidadania), representando o exato oposto do futuro desejado pelas elites. (PEREIRA, 1999, p. 06) 
Havia então uma adesão estética aos padrões e valores europeus e uma relativa aprovação das elites brasileiras em relação ao negro e suas manifestações culturais, pois não ficaria bem essas elites rejeitarem - ao menos publicamente - os elementos constituintes da sua Nação. Sodré argumenta esse comportamento tolerante e sincrético a partir das raízes ibéricas na formação do povo brasileiro, visto que as sociedades com passado colonial precisaram buscar novas justificativas para a sua existência histórica, o que implica uma reinvenção da identidade a partir do rompimento com a colonização europeia.

Jesse Sousa, a partir de Florestan Fernandes, argumenta que com o fim da escravidão houve a inadaptação do negro para o trabalho livre, como reflexo da incapacidade do negro de agir segundo os modelos de comportamento. Sousa enfatiza que não era apenas a cor da pele que causava a marginalização, mas era um fator que se somava à uma personalidade já julgada como improdutiva e que corromperia a sociedade.

A cor da pele, nesse contexto, age, no máximo, como uma ferida adicional à autoestima do sujeito em questão, mas o núcleo do problema é a combinação de abandono e inadaptação, destinos que atingiam ambos os grupos independentemente da cor. No contexto da sociedade escravocrata a cor funciona como um índice tendencialmente absoluto da situação servil...na sociedade competitiva a cor funciona como índice "relativo" de primitividade... (SOUSA, 2003, p. 159)

É o abandono secular do negro à própria sorte que Sousa destaca como a "causa" evidente da sua não adaptação à sociedade. Segundo o autor, este abandono criou condições perversas que eternizaram um "habitus precário", constrangendo esses grupos a uma "vida marginal e humilhante à margem da sociedade incluída" (SOUSA, 2003).

Pereira supõe, a partir disso, que o primeiro momento em que houve um "vislumbre de Cidadania para a população afro-brasileira foi com a promulgação da lei dos $2 / 3$ pelo governo revolucionário de Getúlio Vargas, em 1931" (PEREIRA, 1999). A lei determinava que a cada três empregos, dois deveriam ser de brasileiros. Com isso houve o que o autor chama de "escurecimento sensível no mercado de trabalho". A década de 1930 se afirmava como um marco, um novo bloco de poder nacionalista.

Desde os anos 30, se desenhava lentamente uma nova configuração da situação do negro na sociedade brasileira. A afirmação do valor das suas manifestações culturais; maior visibilidade para a expressão negra nos diversos espaços de criação artísticas, nos esportes; além da presença (ainda como exceção) em alguns setores 
profissionais mais qualificados, eram sintomáticas. Em termos econômicos e sociais, o "milagre brasileiro" [...] criando maiores oportunidades de empregos e qualificação profissional, propiciou uma ampliação acelerada da até então rarefeita classe média negra. Par a par com esta rápida mudança social e de perspectivas, se multiplicavam os choques e disputas inevitáveis destes negros com uma classe média branca (ou branca por auto-definição, na expressão de Darcy Ribeiro), habituada às "áreas reservadas" de emprego, de moradia, de lazer e outras. Além de tudo isto, os "novos" negros contemplavam entusiasmados uma conjuntura internacional sob medida para a projeção dos seus sonhos mais recôndidos: quem não se orgulharia dos êxitos do Movimento pelos Direitos Civis dos negros norteamericanos, que dominou a conjuntura internacional na década de 60... (PEREIRA, 1999, p. 06)

Assim o termo cidadania foi aos poucos sendo incorporado nos discursos dos militantes negros, superando as dificuldades iniciais e dando lugar a novas possibilidades de resignificação dos valores étnicos, em especial nos centros urbanos. Apesar dessa relevância do termo cidadania, o significado ainda é restritivo, sendo inicialmente como uma noção vaga de direitos, direitos que os não negros possuíam (PEREIRA, 1999).

Luiz Oliveira (2004) ressalta que ao menos desde os anos de 1950, a Sociologia vem criticando a ideologia da democracia racial no Brasil, chamando a atenção para a incidência de discriminação no país. O autor afirma que mesmo com a ascensão social, a discriminação racial não é eliminada, ainda que seja reduzida ou suavizada.

Uma das características das práticas de discriminação indireta vigentes no Brasil é que ela costuma aparecer de maneira dissimulada, sendo por vezes de difícil identificação mesmo para aqueles que sofrem na pele os seus efeitos. Além da discriminação ser uma prática ilegal, com penalidades previstas em lei, também é sancionada negativamente no plano moral, e não é de bom tom demonstrar preconceito. Desse modo, mesmo quando não se trata de esconder intencionalmente o preconceito, ele se manifesta freqüentemente de maneira irrefletida e a falta de consciência do ator sobre suas atitudes preconceituosas eventualmente esboçadas não é de todo surpreendente (OLIVEIRA, 2004, p. 82)

Ainda que os direitos básicos de cidadania no Brasil sejam garantidos pela Constituição, eles não são de fato acessíveis ao contingente expressivo da população. Preconceito, discriminação social e racismo são práticas relacionadas e veladas na sociedade brasileira que fazem com que a aceitação do negro seja apenas aparente, conduzindo à negação de direitos.

...apesar de o preconceito contra negros e outros grupos sociais nem sempre se manifestar por meio de atitudes discriminatórias ou de insultos, é muito significativo o percentual de situações em que a mobilização do preconceito tem essa implicação, e mais significativo ainda o percentual de situações nas quais 
aquele que discrimina não tem consciência ou não está alerta para as conseqüências de seus atos no plano dos direitos. A ideologia da democracia racial e a vergonha do preconceito são alguns dos fatores que contribuem para isso, além da dificuldade mais geral, e muito mais abrangente, para internalizar a orientação normativa, de caráter universalista, que prega a igualdade de direitos e a não discriminação entre cidadãos, assim como estabelece a Constituição de 1988. (OLIVEIRA, 2004, p. 86-87)

O autor ressalta que após a abolição da escravatura os negros nunca foram formalmente discriminados, enfatizando o papel do estado na divulgação de uma ideologia da democracia racial. Mas, na vida cotidiana, havia sempre uma grande tensão entre negros e brancos, identificando um espaço privilegiado onde o racismo brasileiro se manifestava e também se escondia.

Cláudia Azevedo (2005) conta que o termo "raça" foi corriqueiro nas elites brasileiras desde meados do século XIX, em referência às descobertas da ciência europeia e norte-americana nesse assunto. Já a ideia de racismo surgiu provavelmente nos anos 1920, quando alguns dos "pensadores críticos do "preconceito de cor" e sensíveis às denúncias do movimento pan-africanista ascendente passaram a pensar sobre a categoria de raça, abandonando a postura tradicional de se pensar a partir dela." (AZEVEDO, 2005). O racismo seria explicado a partir de categorias da natureza ou por antigas construções históricas e sociais. Assim, o conhecimento histórico serviria para nos conformar de algo que já existe na natureza e não para nos liberar de fardos inventados pelos nossos ancestrais.

Como argumenta Azevedo e Nohara (2008), o racismo brasileiro é materializado nos meios de comunicação do mesmo modo como ele está presente na sociedade brasileira: dissimulado. A invisibilidade dos afrodescendentes na mídia ou até mesmo a distorção dos seus retratos é resultado do racismo presente na própria sociedade, contribuindo para mecanismos de exclusão social. “Assim, a invisibilidade na mídia e a estigmatização dos papéis percebida pelos entrevistados podem ser interpretadas como o fruto destas estratégias utilizadas pelo grupo dominante", concluem as autoras.

\section{Mídia e o negrotesco}

Os grandes centros urbanos, frutos da industrialização, caracterizam-se como espaço de diferenças sociais, exclusão, vigilância, economia. Nesse espaço, os meios de informação são uma estratégia política global, dispositivos de mobilização e integração das populações. 
Sodré (1992) destaca que os mass media têm função altamente estratégica na divulgação de inovações capazes de produzir efeitos de homogeneização, sendo dispositivos de administração da sociedade pela organização tecnoburocrática (Estado e grande empresa). A mídia é um produto simbólico, indutora de hábitos, crenças e modos de percepção, com um projeto implícito de reorganização do espaço/tempo social. A mídia, em especial a televisiva, carrega um poder de telerrealidade, que

...reside na forma social por ela engendrada, que é um novo modo de estruturar as relações humanas. [...] novo espaço e tempo acelerado no sentido de globalidade, instantaneidade e simultaneidade. [...] Mídias (televisão) refletem representações sociais geradas por instituições vigentes... (SODRÉ, 1992, p. 39)

Da mesma forma que Sodré, Thompson (2001) conclui que os sistemas simbólicos não são ideológicos por si mesmos. A ideologia é gerada a partir da maneira como os meios simbólicos são utilizados, constituindo assim o que o autor denomina de uso social das formas simbólicas (Thompson, 2001). Assim, os meios de comunicação podem tornar-se ferramentas de reprodução e de transmissão das ideologias de grupos dominantes.

Azevedo e Nohara (2008) enfatizam o papel essencial dos meios de comunicação na construção e reafirmação das identidades individuais, oferecendo modelos de pensamentos e de comportamentos a serem seguidos. As imagens das mídias, afirmam, produzem o efeito do real, fazendo com que os indivíduos creiam no que veem.

Mass media tem função altamente estratégica na divulgação de inovações capazes de produzir efeitos de homogeneização necessários ao processo acumulativo. A despolitização dos conteúdos das mensagens é corolário do sistema informativopublicitário, uma vez que o fenômeno político se revela anti-homogeneizante, por implicar a expressão do conflito entre gurpos divergentes e a escuta de minorias com seus gostos e tendências particulares. (AZEVEDO e NOHARA, 2008, p. 97)

Os mass media são dispositivos de administração da sociedade pelo Estado e pelas empresas, estruturados a partir de uma nova cultura que se converte nos modelos e representações estáveis da vida social. Na mídia os produtos simbólicos são repassados, transmitidos, comunicados, induzindo hábitos, crenças e modos de percepção do sujeito.

Azevedo e Nohara (2008) ressaltam a importância das investigações relacionadas às representações dos afrodescendentes na mídia brasileira, que constituem cerca de $43 \%$ da população segundo dados do Instituto Brasileiro de Geografia e Estatística (IBGE) em 2006. Apesar de uma 
parcela considerável na população, a representação do negro na nos meios de comunicação ainda é pouco expressiva. Tem-se percebido nos últimos anos um número maior de papéis de afrodescendentes na mídia, em especial a televisão brasileira, no entanto os papeis ainda são carregados de estigmas sociais.

Em O Império do Grotesco, Muniz Sodré e Raquel Paiva colocam a televisão como um grande meio de comunicação, mas com espectadores pouco alfabetizados e ávidos por diversão. Nos anos 1990, a informação exposta, como discorre Sodré, tem mais a ver com o imaginário midiático do que com a informação necessária a uma cidadania. A programação televisiva é grotesca, com "representações sociais a partir do senso comum e orientada para a figuração de uma realidade qualquer" (SODRÉ e PAIVA, 2006, p.131).

Entre o individual e o social, essas representações internalizam conteúdos realistas e imaginários relativos à vida cotidiana. A partir das representações, a sociedade midiatizada interpreta os discursos do senso comum, aliados à força de mercado e assimilado pelo público. Essa forma discursiva não necessariamente comunica, mas reforça a representação.

Sodré (1992) expõe que os meios de comunicação e as tecnologias da informação se colocam na sociedade contemporânea como um lugar central de produção do real. Dessa maneira, a informação seria uma maneira de organização (tanto administrativa quanto gerencial) desse espaço social contemporâneo. Isso, segundo Sodré, implica numa "dissolução da socialidade tradicional, hibridação das formas convenientes e montagem de novos dispositivos de controle" (SODRÉ, 1992, p. 80)

Sodré (1992) caracteriza o grotesco como imbuído de um riso cruel; nele antigos objetos de indignação - como miséria, opressão, falta de solidariedade e descaso do poder público - recaem em uma indiferença generalizada. Os risos são compensados por sorteios, prêmios de patrocinadores, perpetuando o sentimento de que nenhuma política pública se interessa ou se compromete com o bem-estar coletivo. A desesperança das classes mais baixas é amenizada por jogos, numa espécie de "circo contínuo".

...o grotesco aparece como algo nascido da comparação entre a aparência imediata e o segredo das coisas. Aparece, portanto, como ameaça ao ideal, na medida em que obriga o olhar a focar-se nas estruturas da realidade, que então se mostra convulsiva, não necessariamente bela, mas outra. (SODRÉ, 1992, p. 95) 
Levando para a representação do negro, a estesia grotesca corresponde a um caos ou turbulência em um dado sistema de valores. No grotesco, é destacado nas imagens do popular um princípio de vida material e corporal, com imagens extremamente exageradas do corpo, da comida, da satisfação das necessidades naturais e da vida sexual. O que é imposto pela cultura oficial como sublime é rebaixado grotescamente pelo deslocamento para os planos material e corporal. "É essa heterogeneidade, em geral aculturadora, que faz o grotesco emergir como estesia adequada para se pensar a hibridação das formas de cultura popular com a erudita no Brasil”, afirma Sodré.

A questão da mistura se dividia entre a sociedade de consumo emergente e a população diferenciada das grandes cidades, cuja maioria era excluída socialmente. Os excluídos, em grande parte de negros, mestiços ou migrantes nordestinos, eram classificados pelo mercado como categorias socioeconômicas de terceira e quarta ordens. No entanto, eles representavam um potencial de $70 \%$ da audiência dos programas de televisão (SODRÉ 1992). Era um público a ser conquistado pelas emissoras de tevê atraindo a publicidade das empresas.

No grotesco televisivo, a dissonância risível é produzida pela exasperação da heterogeneidade de elementos pertencentes a modos de socialização e de produção cultural diversos. Mesclados com os códigos culturais europeus por obra da tecnologia, os conteúdos das culturas negras, indígenas, cordelescas, gerava, efeitos ingênuos e popularescos, fomentando entretanto a mais aceitação dos programas por parte de um público cuja memória afetiva ainda se achava bastante marcada pelos trações de outras formações simbólicas. O exagero, a profusão, o excesso, o monstruoso - características do grotesco - surgiam como atrações de uma programação animada por uma nova tipologia de personagens, que ia desde o palhaço estilizado até o camelô adaptado à cena eletrônica. Nos programas de auditório da estética predominantemente grotesca, os jogos, os sorteios, as variedades televisivas tinham muito em comum com os espetáculos de feira livre, com festas e ritos das cidadezinhas do interior. (SODRÉ, 1992, p. 100-101)

$\mathrm{Na}$ relação com a televisão, Sodré aborda a família como uma modelagem semiótica das situações do cotidiano, favorecendo a interação dos personagens na trama da tevê. A reprodução de um sujeito íntimo é identificada pelo receptor da teve, é familiarizada com as relações cotidianas. Em países subdesenvolvidos como o Brasil, destaca Sodré, a condição de vida social em que a pobreza sobrevive é refletida no ethos urbano. Nessa sociedade, a criminalidade é decorrente da degradação das instituições tradicionais; não existe uma fronteira nítida entre a criminalidade e a sociedade global organizada.

Essa violência interna encontra um suporte expressivo no grotesco, onde habitam personagens marcantes na cultura ocidental. São papéis como o do louco, palhaço, vagabundo que 
fazem a consciência iludida do público sorrir dos seus próprios enganos ou assumir a existência como farsa (SODRÉ, 1992).

O negrotesco configura-se, entretanto, como anomalias ou aberrações sem efeitos históricos, como algo sem virtualidade trágica, porque já surge como figura de um campo intensivamente equacionado por uma ordem tão operativa (tecnoburocrática) que já não dá lugar à lucidez pelo escândalo de estrutura. $\mathrm{O}$ traço grotesco continua a ser adequação monstruosa de disparidades, mas no quadro de uma indiferença estrutural à deformação das regras e das cenas 9que ajudaram a constituir o sujeito moderno) e à frieza do controle estatístico das populações. (SODRÉ, 1992, p. 110)

Nos meios de comunicação de massa, os cidadãos "discrimináveis", diz Sodré, geralmente são apresentados em filmes, programas de entretenimento ou de informações ora como vilões, ora como cidadãos de segunda classe, com atividades socialmente inferiorizadas. Às vezes são retratados apenas como excluídos, num contexto cultural em que cada vez mais estão presentes representações visíveis num espaço publicitário-mercadológico. Nesse espaço, a visibilidade do negro é essencialmente negativa, o discriminável é automaticamente o suspeito.

A montagem dos meios de comunicação contribui para reforçar estereótipos presentes na memória coletiva da sociedade. São novos tipos de discriminação que se superpõem às formas tradicionais de exclusão social, geralmente abarcadas no termo racismo.

Por isso, ainda que fortemente individualizada, a consciência racista opera com representações comuns a um certo grupo, que se experimenta como "comunidade", no sentido originário de agregação humana constituída por laços de sangue, religiosos, profissionais, territoriais. Para tal consciência, haveria uma comunidade "europeia" autopercebida a partir de parâmetros simbólicos...territoriais e tecnológicos [...]. A cor da pele é o critério imediato da percepção; e o racismo, um suposto saber imediato sobre o outro, por sua vez oposto imaginariamente a um fetiche de homogeneidade construído pela também suposta comunidade étniconacional. (SODRÉ, 1992, p. 119)

Sodré argumenta que o racismo expressa uma tensão entre a aproximação de uma identidade e uma diferença, como no caso de um europeu e um africano. Nesse quadro social a identidade se imagina extremamente superior à diferença, em razão de discursos sobre ciência, tecnologia e religião. Assim, a consciência racista, utilizando esses discursos, desenvolve traços obsessivos na atuação doutrinária, perseguindo ideais de limpeza biológica e territorial. 
A violência desenha-se como recurso frequente no horizonte dessa consciência, porque o outro (objeto da exclusão racial) próximo é percebido como uma ameaça à identidade do grupo grandiosa auto-atribuída pela fantasiosa "comunidade branca". As agressões racistas resultam de uma defesa narcísica dessa suposta identidade. (SODRÉ, 1992. p. 120)

Apesar da modernização gerada pelos meios de comunicação contemporâneos, o problema racial não foi tratado na sua essência. O racismo foi modernizado, nas palavras de Sodré, pela mídia, que acrescentou à rejeição tradicional do outro novas formas de discriminação. Os estereótipos étnicos e representações excludentes dos indivíduos se perpetuam na mídia, como integrantes de uma cultura subalterna. "Os excluídos [...] quando incorporados, entram geralmente na categorização do grotesco", conclui Sodré.

\section{Considerações}

Em uma leve retrospectiva pelos fatores históricos que compõem a nação brasileira e o espaço do negro nessa sociedade percebemos, neste breve estudo, que o racismo ainda está intrínseco na sociedade atual, como esteve mais nitidamente ao longo de décadas. Após a abolição da escravatura, o negro continuou sendo marginalizado socialmente, neste momento mais como um reflexo do seu histórico de escravo e das características do homem livre ingressante no mercado de trabalho.

Para a comunidade negra, que teve também sua história na luta por direitos e reconhecimento de identidades, a cidadania, inicialmente tratada como acesso aos mesmos direitos dos brancos, galgou com o tempo o reconhecimento das diferenças, que é o que torna o negro um brasileiro, parte da nação, com seus costumes, ritos, crenças, peculiaridades.

Ainda há muitas conquistas nesse assunto, pois o racismo dissimulado se perpetua na sociedade e também nos meios de comunicação. O grotesco, como diz com propriedade Muniz Sodré, também se estende aos negros (negrotesco), cujas representações na mídia televisiva são sempre marginalizadas, reforçando estereótipos de uma classe subalterna. Uma luz apontada por Sodré é a necessidade de uma educação para a televisão, ou seja, pensar o papel da mídia na formação da cidadania. A partir disso poderia ser vislumbrada uma representação que não fosse marginal, mas que incluísse o negro - e também outros grupos discriminados - numa posição de igual, apesar das suas diferenças históricas, culturais e econômicas. 
Fischman e Hass (2012) argumentam que "está implícito na crença de que um sujeito mais educado faz um cidadão melhor o reconhecimento de que ninguém nasce com habilidades e aptidões de cidadania. Todos nós precisamos aprender a como ser um cidadão." Para eles, complementando Sodré, o acesso à cidadania pela da educação é possível junto à experiência diária, que é onde as diferenças são assinaladas e devem ser respeitadas. O conceito de cidadania, antes reduzidos a um conjunto de práticas, dispositivos e ideais, é constantemente modificado, influenciado por um novo espaço social, influenciado pelo mercado, pelas novas relações, pela tecnologia e pela mídia.

Artigo submetido em 20/09/2013 e aceito em 01/10/2013.

\section{Referências}

AZEVEDO, C. M. M. A recusa da raça: anti-racismo e cidadania no Brasil dos anos 1830.

Horizontes Antropológicos, Porto Alegre, ano 11, n. 24, p. 297-320, jul./dez. 2005. Disponível em: <http://www.scielo.br/pdf/ha/v11n24/a13v1124.pdf>. Acesso em 03 jul. 2013.

AZEVEDO, C. R; NOHARA, J. J. Interpretaçőes sobre os retratos dos afro-descendentes na mídia de massa. RAC, Curitiba, Edição Especial 2008, p. 119-146. Disponível em <http://www.scielo.br/pdf/rac/v12nspe/a06v12ns>. Acesso em: 03 jul. 2013.

FISCHMAN, G. E.; HASS, E. Cidadania. Educ. Real., Porto Alegre, v. 37, n. 2, p. 491-508, maio/ago. 2012. Disponível em http: <//www.scielo.br/pdf/edreal/v37n2/07.pdf>. Acesso em 04/07/2013.

OLIVEIRA, L. R. C. Racismo, direitos e cidadania. Estudos Avançados, v. 18, n. 50, 2004. Disponível em: <http://www.scielo.br/pdf/ea/v18n50/a09v1850.pdf>. Acesso em: 03 abr. 2013.

PEREIRA, A. M. Construção etnocêntrica do conceito de cidadania. Rio de Janeiro, 1999. Mimeo. Disponível em: <https://www.google.com/url?sa=t\&rct=j\&q=\&esrc=s\&source=web\&cd= 1\&ved=0CCwQFjAA\&url=http $\% 3 \mathrm{~A} \% 2 \mathrm{~F} \% 2 \mathrm{Fbibliotecavirtual.clacso.org}$. ar $\% 2 \mathrm{Far} \% 2 \mathrm{Flibros} \% 2 \mathrm{Fal}$ adaa\%2Fmendes2.rtf\&ei=Q1jbUaySKoiG9gSc_oGoDg\&usg=AFQjCNFNcg4jEkgo8-mR-ZgpcNiAovYzw\&sig2=BxT2V7vfeuxm2YSK2bYKhw>. Acesso em: 02 jul. 2013

SODRÉ, M. A máquina de narciso. São Paulo: Cortez, 1994.

SODRÉ, M. As estratégias sensíveis: afeto, mídia e política. Petrópolis, RJ: Vozes, 2006.

SODRÉ, M. Antropológica do espelho: uma teoria da comunicação linear. Pretópolis, RJ: Vozes, 2002.

SODRÉ, M. Claros e escuros: identidade, povo e mídia no Brasil. Petrópolis, RJ: Vozes, 1999. 
SODRÉ, M. O social irradiado: violência urbana, negrotesco e mídia. São Paulo: Cortez, 1992. SODRÉ, M.; PAIVA, R. O império do grotesco. Rio de Janeiro: Mauad, 2006.

SOUSA, J. A construção social da subcidadania: para uma sociologia política da modernidade periférica. Belo Horizonte: Editora UFMG; Rio de Janeiro: IUPERJ, 2003.

THOMPSON, J. A mídia e a modernidade. Petrópolis, RJ: Vozes, 2012. 